\title{
NFL Regimen
}

National Cancer Institute

\section{Source}

National Cancer Institute. NFL Regimen. NCI Thesaurus. Code C161990.

A chemotherapy regimen consisting of fluorouracil, leucovorin, and mitoxantrone that

may be used in the treatment of metastatic breast cancer. 